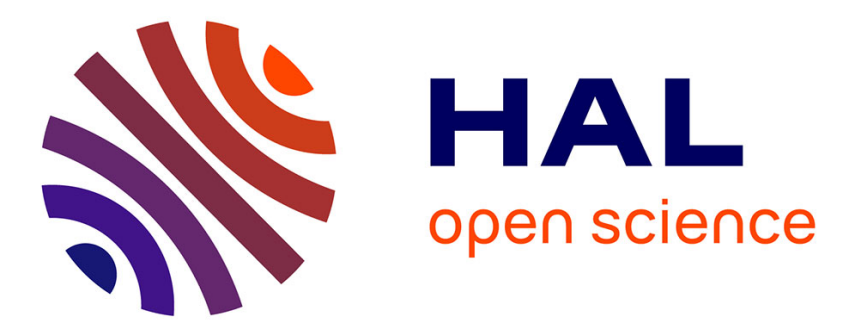

\title{
Selection of authentic modelling practices as contexts for chemistry education
}

\author{
Gjalt Prins, Astrid M.W. Bulte, Albert Pilot, Jan van Driel
}

\section{To cite this version:}

Gjalt Prins, Astrid M.W. Bulte, Albert Pilot, Jan van Driel. Selection of authentic modelling practices as contexts for chemistry education. International Journal of Science Education, 2008, 30 (14), pp.1867-1890. 10.1080/09500690701581823 . hal-00513358

\section{HAL Id: hal-00513358 \\ https://hal.science/hal-00513358}

Submitted on 1 Sep 2010

HAL is a multi-disciplinary open access archive for the deposit and dissemination of scientific research documents, whether they are published or not. The documents may come from teaching and research institutions in France or abroad, or from public or private research centers.
L'archive ouverte pluridisciplinaire HAL, est destinée au dépôt et à la diffusion de documents scientifiques de niveau recherche, publiés ou non, émanant des établissements d'enseignement et de recherche français ou étrangers, des laboratoires publics ou privés. 


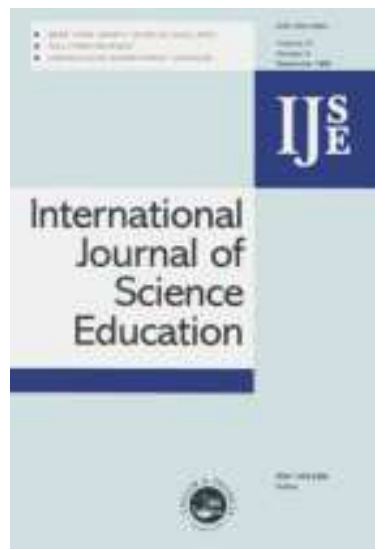

\section{Selection of authentic modelling practices as contexts for} chemistry education

\begin{tabular}{|r|l|}
\hline Journal: & International Journal of Science Education \\
\hline Manuscript ID: & TSED-2006-0250.R2 \\
\hline Manuscript Type: & Research Paper \\
\hline Keywords: & chemistry education, secondary school, design study \\
\hline Keywords (user): & modelling, authentic practices \\
\hline \multicolumn{2}{|l}{} \\
\hline
\end{tabular}

\section{今 ScholarONE" \\ Manuscript Central}


Selection of authentic modelling practices as contexts for chemistry

education

\begin{abstract}
In science education, students should come to understand the nature and significance of models. In case of chemistry education it is argued that the present use of models is often not meaningful from the students' perspective. A strategy to overcome this problem is to use an authentic chemical modelling practice as a context for a curriculum unit. The theoretical framework for this strategy is activity theory rooted in sociocultural theories on learning. An authentic chemical modelling practice is characterized by a set of motives for model development through a well defined modelling procedure using only relevant issue knowledge. The aim of this study was to explore, analyse and select authentic chemical modelling practices for use in chemistry education. The suitability of the practices was reviewed by applying a stepwise procedure focussed on criteria such as students' interest and ownership, modelling procedure, issue knowledge and feasibility of the laboratory work in the classroom. It was concluded that modelling drinking water treatment and human exposure assessment are both suitable to serve as contexts, because both practices exhibit clear motives for model construction and the applied modelling procedures are in line with students' preexisting procedural modelling knowledge. The issue knowledge involved is consistent with present Dutch science curriculum and it is possible to carry out experimental work in the classroom for model calibration and validation. The method described here to select and evaluate practices for use as contexts in chemistry education can also be used in other science domains.
\end{abstract}




\section{Introduction}

Models are essential to the production, dissemination, and acceptance, of scientific knowledge

(Giere, 1988). It therefore seems appropriate that models play equally important roles in

science education (Gilbert \& Boulter, 1998; Hodson, 1992). Learning to understand the nature and significance of models is regarded as being central to science education. At present, models and modelling are considered integral parts of scientific literacy. However, the study of Grosslight, Unger, Jay and Smith (1991) revealed that students generally do not clearly distinguish the ideas and/or purposes underlying models, the content of the models, and the experimental data which support or refute the validity or usefulness of models. Instead, students usually view models as toys or miniatures of real-life objects, and few students understand why models are used in science (Ingham \& Gilbert, 1991). Students generally do not give meaning to the process of modelling. While these problems are apparent in different science education domains, in this paper we concentrate specifically on chemistry education.

The described learning problems related to models and modelling do apply to a variety of models used in chemistry education (Harrison \& Treagust, 2000), such as iconic and symbolic $\underline{\text { models }}$ to depict chemical formulae and chemical equations, mathematical models to represent conceptual relationships of physical properties and processes (e.g. PV = nRT) and theoretical models to describe well-grounded theoretical entities (e.g. kinetic theory model of gas volume, temperature and pressure). In this paper we use the term model as some structured representation, including symbolic elements, of the essential characteristics of an idea, object, event process or a system (Gilbert \& Boulter, 2000). In addition, we define the act of modelling as the construction, evaluation and revision of a model in response to a particular task (Gobert \& Buckley, 2000).

The conventional chemistry curriculum emphasises students' acquisition of conceptual information and declarative knowledge on models (Duschl \& Gitomer, 1997; Erduran, 2001). Within this traditional setting, the motivation, strategies and argumentation underlying the 
development, evaluation and revision of models are neglected, and therefore remain unclear to students (Erduran \& Duschl, 2004). Given this situation of utilisation of models it is not surprising that many students have difficulties seeing the meaningfulness of models and modelling.

Students need to gain an understanding of how and why models are constructed and what modelling process is utilised. We concur with Erduran and Duschl (2004) that the experienced lack of meaningfulness requires a redesign and a redefinition of the trajectory of learning models and modelling. Instead of providing students with models designed by others and uncovering facts to be memorised, the focus should be on the process of modelling and the use of models. The learning of models and modelling must be legitimised from a student's perspective (Roth, 1996; Sabelli, 1994). In addition, they should become involved in a modelling process in which their understanding contributes to the development of their models and the evaluation and testing of their models contributes to evolving understanding (Penner, Lehrer, \& Schauble, 1998; Roth, 1998). This can be achieved if the students' learning is positioned within a well selected context in which a modelling approach is inextricably linked to recognisable real-world problems and societal issues from students' perspective (Bennett \& Holman, 2002; Edelson, 1998). By means of such a context students are expected to recognise that chemistry, including its models, matters for society and thus can be relevant for themselves. In fact, engaging students in a context in which they employ authentic model-based tasks has proven to promote the students' understanding of the role and functioning of models in science (Gobert \& Pallant, 2004).

Within this perspective we position the challenges for learning models and modelling within the broader international development of context-based science education (Bennett \& Holman, 2002; Pilot \& Bulte, 2006). However, as promising this strategy might be, it has remained difficult to implement these challenges within the classroom. Part of the problem is that the idea of context-based chemistry education has been used in different meanings (Gilbert, 2006; Van Oers, 1998). The numerous interpretations of the term context evoke 
some important educational design questions, such as which contexts are suitable for learning models and modelling in chemistry education? What are the essential features of these contexts that need to be implemented in a learning process? How to evaluate the context upon its potential use in chemistry education? To address these design problems contexts need to be identified in which models are employed in a meaningful way. These should be analysed to reveal the essential features and evaluated with respect to learning models and modelling in chemistry. These are the key objectives addressed in this paper.

\section{Authentic chemical practices as contexts}

In our interpretation of contexts, we use authentic chemical practices for the design of meaningful learning environments(Bulte, Klaassen, Westbroek, Stolk, Prins, Genseberger, De Jong, \& Pilot, 2005; Bulte, Westbroek, De Jong, \& Pilot, 2006; Westbroek, 2005). In our society many chemistry-related practices are available. For example, practices aimed at quality evaluation of products, e.g. drinking water, food or consumer products for personal health, or practices with an emphasis on research, e.g. developing new catalysts or acquiring fundamental understanding of structure-property relations of proteins. We define an authentic practice as a homogeneous group of people working on real-world problems and societal issues in a 'community' connected by three characteristic features (Bulte et al., 2005):

A. having common motives and purposes, e.g. evaluation of the quality of a product or development of a new product,

B. working according to a similar type of characteristic procedure leading to an outcome, e.g. procedure for quality assessment or design procedure,

C. displaying apparent necessary knowledge about the issue they work on, e.g. chemical concepts (or science concepts in broader perspective),

Within such a practice the specific attitudes, characteristic procedures and issue knowledge play a natural role. The relevance of the skills and issue knowledge involved is not questioned, since the participants of such a practice have clear motives to use and extend 
these accordingly. In an authentic practice people connect the three above features in a meaningful way.

Using an authentic practice as a context for chemistry education involves the implementation of the essential set of motives and purposes, the characteristic procedure and relevant issue knowledge in curriculum units. If we manage to actively involve learners in a practice and perform activities within this practice, they are expected to appreciate the implications of the concepts and give appropriate meanings (Psarros, 1998). Authentic practices can be used as sources of inspiration for designing a sequence of learning activities such that students see the point of what they are doing and have motives to extend their knowledge at every step in the teaching - learning process. This consistency between the learning activities reflects the coherency in the flow of activities in an authentic practice. This view on, and use of, authentic practices in education for the design of meaningful learning processes, stems from, and closely relates to activity theory in education. Activity theory (Engestroem, 1987; Leont'ev, 1978; Van Aalsvoort, 2004) builds on principles of sociocultural theories on learning (Van Oers, 1998; Vygotsky, 1978). Activity theory describes society in terms of connected social practices as manifestations of activity. The unit 'activity' is considered the foundation of knowledge. Rooted in sociocultural theories on learning, activity theory considers the zone of proximal development as a core concept, in which development involves cognitive, affective and volitional aspects. Identifying students' cognitive, affective and volitional aspects in respect of an activity to be studied is a major task to be addressed (Confrey, 1995).

The challenge in adapting an authentic practice for use in education is to maintain authenticity and achieve coherency within the constraints of the classroom environment. The adapted authentic practice for students must reflect a similar set of the three characteristic features for two essentially different populations of learners and experts. Some differences to account for are other interests and dissimilar motivation for involvement into certain issues. Moreover distinct pre-existing procedural knowledge of experts, which students do not possess, 
regarding the pattern of activities can lead to an outcome (e.g. solution for a problem, product). Consequently, not all authentic practices are equally suitable for use in chemistry education. There is need for explicit selection criteria to analyse and evaluate to what extent authentic practices are within students' zone of proximal development. In this particular study we aim to contribute to the development and use of such criteria by analysing in detail some authentic chemical modelling practices. We specifically focus on authentic chemical modelling practices in which the models are used as tools for prediction. Insight into the predictive potential of models is considered important to be able to judge the quality of models, but is not fully utilized in present chemistry (or science) education (Harrison \& Treagust, 2000; Treagust, Chittleborough, \& Mamiala, 2002).

\section{Criteria for selection of authentic modelling practices as contexts}

We formulate a set of criteria for selection of authentic chemical modelling practices with the aim to develop context-based units for meaningful learning of models and modelling. These criteria are based on the three characteristic features of authentic modelling practices. On each feature we give an overview of cognitive, affective and volitional aspects to account for from the students' point of view based on literature. These aspects in turn give rise to explicit criteria, which are then used to evaluate whether the corresponding feature of selected authentic modelling practices is within the students' zone of proximal development. Furthermore we have formulated a conditional criterion focussing on laboratory work in the classroom. Models are inseparably linked to empirical data. In most authentic chemical modelling practices empirical data is collected at a certain particular stage for model construction, revision, validation or calibration. To maintain authenticity the laboratory work in the authentic practice should also be feasible within the constraints of a classroom. 
Feature A: Motives and purposes

To assess the operational capacity of feature A we discuss two specific aspects of students' involvement into certain issues: interest and ownership.

Osborne and Collins (2001) investigated students' attitudes on school science curriculum, the aspects the students found interesting and valuable, and their views about current content. Their study reported that many students perceive school science to be dominated by content with too much repetition and too little challenge. On the other hand the study showed that most of the students recognise the importance of science and its influence on society. Osborne and Collins concluded that students can become interested and motivated in issues when they perceive an immediate relevance and practical work, provided that these are implemented in challenging teaching materials and with high-quality teaching. Students suggested that there was a need for more contemporary examples in order that school science addresses, at least occasionally, the same issues as science in the media. We thus define criterion A1 (students' interest): students are interested in and motivated for a certain issue.

In addition, several studies have concluded that students' involvement will raise if pupils are able to take control of their learning and develop both knowledge and personal autonomy with the issue at hand (Donnelly, 2001). This aspiration might be realised if students are given opportunities to conduct open-ended investigations in which the students own judgements, case making and interpretations are brought to the fore. In the present case, conditional for students to develop ownership is that they themselves see the point of modelling. So, the authentic motives and purposes for modelling should be recognisable for students. This leads to formulation of a second criterion A2 (students' ownership): students can develop ownership and personal autonomy with a certain issue. 
Feature B: Characteristic modelling procedure

The characteristic modelling procedure in the authentic practice, feature $\mathrm{B}$, is of special importance because it should provide for coherence when sequencing modelling activities in the classroom. This flow of modelling activities should be recognisable from the perspective of students to achieve a meaningful learning process. Hence, it is necessary to evaluate to what extent the characteristic modelling procedure fits with the students' common sense notions and pre-existing procedural modelling knowledge. The Modus project, a collaboration between the Advisory Unit for Micro technology in Education and King's College London, focusing on implementing computer-based modelling across the curriculum, outlined a modelling process for general application, as depicted in Figure 1 (Webb, 1994).

\section{[Insert Figure 1 about here]}

Webb (1994) tested this modelling process for general application in primary schools among students aged 8-11. The results showed that students successfully employed the modelling stages as outlined, provided that they were familiar and knowledgeable with the subject matter (see also the criteria as formulated for feature C.). These findings are in line with other research studies showing that children learn and use models from an early age onwards (Schauble, Klopfer, \& Raghavan, 1991). Furthermore, it demonstrates that there is no fundamental difference between the thinking of children and adults (experts), except when accounting for domain specific knowledge (Carey, 1985; Kuhn, 1989). In conclusion, we will compare the main stages in the characteristic modelling procedure in an authentic practice with the stages in the proposed modelling procedure for general application. In case of resemblance, we expect that the characteristic modelling procedure is in line with students' pre-existing procedural modelling knowledge.

We therefore formulate criterion B (modelling procedure): The main stages in the characteristic modelling procedure in an authentic practice are in line with the stages in the proposed modelling procedure for general application. 


\section{Feature C: Issue knowledge}

Experts use specific issue knowledge to act competently in an authentic practice. Students will have to learn the same issue knowledge in the instructional version of the authentic practice, yet consistent with and linked to established science knowledge. Students' cognitive state consists of two areas: they have a certain knowledge base, consisting of domain and general knowledge, and a skills base, which is the repertoire of cognitive activities the students master at that moment (Hmelo-Silver, Nagarajan, \& Day, 2002; Schunn \& Anderson, 1999). Although knowledge and skills are mentioned as separate domains, it is broadly recognised that these are used interlinked. Thus, the issue knowledge and skills to be learnt by students should be within students' capacities, and preferably such that they can be productively built on students' initial cognitive state. Although knowledge and skills required in cognitive tasks may vary widely, primarily two factors evolve as being more important: the complexity and familiarity (Taconis, Ferguson-Hessler, \& Broekkamp, 2001). The complexity depends on the number of variables involved and number of sub-problems to be solved to reach an outcome. The familiarity depends on the amount of known knowledge and routine skills versus the amount of new information in the situation presented. We therefore define two specific aspects to evaluate the involved issue knowledge in authentic modelling practices:

Complexity (C1): Students must be able to deal with the complexity of the issue Familiarity (C2): Students must be familiar with the issue.

\section{Conditional criterion D: Laboratory work in the classroom}

By means of experiments empirical data is collected for model construction, revision, validation or calibration. However, conducting experiments in classroom is restricted in several ways. Firstly, one should pay attention to the working and safety conditions, both in agreement with legislation. Secondly, the duration of the experiments should not be too long, 
preferably within a few hours, to ensure finishing the laboratory work in one lesson. Thirdly, the school should have suitable equipment, or if not, the necessary equipment should not be too expensive. The same applies for chemicals to be used. Finally, the preparation time needed from the staff should be reasonable compared to the length of the experiments. Taken together, the above mentioned aspects with respect to laboratory work leads to a conditional criterion for the selection of feasible practices: laboratory work must be feasible in the classroom (D).

In fact, besides the conditional criterion D, the criteria A1 / A2, B and C1 / C2 evaluate whether the features A, B \& C of authentic practices are close enough to students interests, modelling abilities and their pre-existing knowledge base. In activity theory the socially accepted attributes of an authentic practice are brought together as far as these are recognised from the perspective of students. Starting from this recognition, students should enter the zone of proximal development. Put another way, the selected authentic modelling practices should provide students with just enough challenges to extend their knowledge of modelling.

\section{Scope and research questions of this study}

In this study we focus on the selection, analysis and evaluation of authentic practices for the design of a context-based unit about modelling intended for students aged 16/17 years, grade 11 (third year of the chemistry course), in The Netherlands. The following specific research questions are addressed in this research study:

1. In what authentic chemical practices are models used as a predictive tool?

2. To what extent do these authentic chemical practices meet a subset of the criteria, namely students' interest (A1), complexity of the issue (C1), familiarity with the issue (C2) and the feasibility of the laboratory work in the classroom (D)? 
3. What are, for each of the selected authentic chemical practices, the motives and purposes

\section{Method}

Given the purpose of this study, the data required are essentially qualitative. Authentic practices for educational purposes were searched, selected and analysed in four consecutive steps. Each of the four steps corresponds to answering research question 1 till 4 in turn. Firstly, a list of authentic chemical practices was generated by internet search. Secondly, these practices were evaluated according to the criteria students' interest (A1), complexity of the issue $(\mathrm{C} 1)$, familiarity with the issue $(\mathrm{C} 2)$ and feasibility of the laboratory work in classroom (D). Thirdly, the selected practices from the second step were analysed in detail using relevant documents (reports, articles) and by expert-interviews. The aim was to gain more insight into the authentic chemical modelling practices with respect to the three characteristic features. Fourthly, the results of the in-depth analysis of the authentic chemical modelling practices were evaluated according to all criteria. Below each step is described in more detail. 
Research question 1: In what authentic chemical practices are models used as a predictive tool?

In this first step, an internet search was conducted to find authentic chemical practices in which models are employed as predictive tools. The search was conducted by one researcher (first author of this article) in January 2004 with search machine Google using a combination of the keywords 'modelling', 'procedure', 'predictive', 'chemistry' and 'practices'. These keywords were derived from our theoretical framework. Our rationale for using this very open search method was to acquire a broad range of authentic chemical modelling practices, including social, technological and research practices. Given concerns about the reliability of some internet resources, the validity of this search method was ensured by selecting only references to well established institutes, e.g. companies or governmental authorities. Solely Dutch websites were included in our search, since Dutch practices were expected to be more recognisable for Dutch students.

Research question 2: To what extent do these authentic chemical practices meet a subset of the criteria, namely students' interest (A1), complexity of the issue (C1), familiarity with the issue (C2) and feasibility of the laboratory work in the classroom (D)?

Each practice found in the previous step was elaborated using information found during the internet search. The information retrieval was carried out by one researcher (first author). Using this information each practice in turn was reviewed according to a subset of the criteria.

This review process was conducted independently by two researchers (first and second author). Next, both researchers compared and discussed their judgements on each criterion per practice resulting in a final judgement, which then was reviewed in the full research team (all authors) yielding a decision about which practices to be analysed in detail in the third step. 
Research question 3: What are, for each of the selected authentic chemical practices, motives

and purposes to construct models (feature A), the characteristic modelling procedures for developing such models (feature B) and the related issue knowledge (feature C)?

In this third step, each of the selected practices were analysed in depth using relevant literature to gain more insight in the characteristic features of each authentic practice. This literature study was performed by one researcher (first author). The outcomes of this analysis were discussed with a second researcher (second author). Next a semi-structured expertinterview was designed and again evaluated with a second researcher. The purpose of the expert-interview was to check whether our interpretation of the motives and purposes for model construction (feature A), characteristic modelling procedures (feature B) and issue knowledge (feature C) involved were correct and complete. The interview outline is listed in Table 1. Next the interview was conducted with one expert per practice. The expert was chosen based on his (or her) in-depth background knowledge on the practice, evidenced by being (co-)author of selected literature. All experts were employed at well-established Dutch institutes in research positions or in charge of a research team. The length of the interview was approximately 90 minutes. The interview was audio-taped and transcribed verbatim. Afterwards the expert was given the opportunity to check the transcript. The interview data were analysed from an interpretative perspective (Smith, 1995). The focus was on the expert's statements concerning the motives and purposes for model construction (feature A) and issue knowledge (feature C), and the expert's response and feedback on the proposed characteristic modelling procedure (feature B). The analysis was conducted by two researches (first and second author) independently, after which the selected statements and feedback were compared and differences in interpretation were discussed. The combined results were again submitted to the expert for final comments, resulting in a complete and thorough description of the practices with respect to features A, B and C. 
Research question 4: To what extent do these detailed studied authentic chemical practices meet all criteria for selection as contexts for chemistry units?

Each authentic chemical modelling practice studied in the previous step was evaluated according to all criteria: students' interest (A1), students' ownership (A2), characteristic modelling procedure $(B)$, complexity of the issue $(\mathrm{C} 1)$, familiarity with the issue $(\mathrm{C} 2)$ and feasibility of the laboratory work in the classroom (D). This review process was (again) conducted independently by two researchers as described in step 2 (see research question 2). The resulting judgements of both researchers were discussed in the full research team (all authors) for a final decision which modelling practices are usable for designing curriculum units for meaningful learning of models and modelling.

\section{Results}

The results will be presented according to the steps described in the method section.

Research question 1: In what authentic chemical practices are models used as a predictive tool?

The internet search yielded a range of issues in the field of science, engineering and technological enterprises. The first run through Dutch websites with Google using keywords ‘modelling', 'procedure', 'predictive', 'chemistry' and 'practices' resulted in 120 hits. This search result was refined by eliminating all issues not containing laboratory work by filtering using keywords 'experiments' and 'laboratory work'. This procedure left about 45 links to be visited separately. These links to issues were roughly evaluated on the state of the presented work (starting phase, ongoing project or finish work) and type of laboratory work done. All links to issues in the starting phase were eliminated, for example, those yet to be or recently approved, proposals for development of new modelling techniques. Also issues in which the laboratory work was very complex or only feasible using advanced equipment were 
abolished, for example molecular modelling using advanced computer tools. This elimination left 29 issues to take into account. Finally, these 29 issues were clustered depending on the type of topic dealt with, eventually resulting in seven practices to be evaluated. These seven practices are short described in Table 2.

\section{[Insert Table 2 about here]}

At this point two remarkable aspects could be identified within the list of authentic practices resulting from the internet search. Firstly, all practices found tend to have a multidisciplinary character, in which several science or technology domains are involved, beyond the 'pure' chemical domain. Secondly, the types of models emerging from the found practices are, in fact, mathematical equations, depicting conceptual relationships between chemical concepts. This could be due to our emphasis on the predictive function of the model, since mathematical models are considered the most accurate and predictive of all models (Harrison $\&$ Treagust, 2000).

Research question 2: To what extent do these authentic chemical practices meet a subset of the criteria, namely students' interest (A1), complexity of the issue (C1), familiarity with the issue (C2) and feasibility of the laboratory work in the classroom (D)?

Based on the information gathered the seven practices were reviewed according to a subset of the criteria. In four practices, namely climate modelling, model-based predictive control of food production, modelling emissions of volatile organic substances and modelling a biogas installation, little opportunities were seen to implement experiments in classroom, thus resulting in a negative judgement on criterion $\mathrm{D}$ in this particular project. In addition, the practices climate modelling and model-based predictive control of food production were judged low on criteria complexity (C1) and familiarity (C2). The issue knowledge involved (feature C) in these two practices was considered not within the zone of proximal development of students. Likewise, the practice modelling emissions of volatile organic $\underline{\text { substances }}$ was judged negatively on motives and purposes for model construction (feature 
A). This practice dealt with volatile organic substances in factory environments only, which was considered not to be within the students' zone of interests. The results are summarised in Table 3 .

\section{[Insert Table 3 about here]}

With respect to the conditional criterion feasibility of the laboratory work (D), three practices were judged to comply: microbiological risk assessment, modelling drinking water treatment and human exposure assessment. Especially in case of modelling drinking water treatment many opportunities were seen for laboratory work, due the availability of 'ready to use' experiments related to water treatment for use in classroom (Jacobsen, 2004). The three practices microbiological risk assessment, modelling drinking water treatment and human exposure assessment were also expected to score high on students' interest due to dealing with issues students themselves frequently encounter in daily life: food, drinking water and all kinds of consumer products. The judgement on criteria complexity $(\mathrm{C} 1)$ and familiarity $(\mathrm{C} 2)$ for these three practices was sufficient with respect to use in chemical education at this stage of analysis.

After this first evaluation step three practices were judged to comply with all the applied criteria. Each practice was studied in detail in the third step to reveal the characteristic features.

Research question 3: What are, within the selected authentic chemical practices, the motives and purposes to construct models (feature A), the characteristic modelling procedures for developing such models (feature B) and the related issue knowledge (feature C)?

In this section the combined results of literature study and expert-interviews are presented of the practices microbiological risk assessment (Den Aantrekker, 2002), modelling drinking water treatment (Versteegh, Van Gaalen, Rietveld, Aldenberg, \& Cleij, 2001) and human exposure assessment (Van Veen, 2001). We consulted experts from the National Institute of Public Health and the Environment and Wageningen University. The internet search revealed 
references to these institutes. Both institutes are well known in The Netherlands as being concerned with mentioned topics of the practices. Since the focus during analyses was on motives and purposes, characteristic modelling procedure and issue knowledge, the results are described in that order.

Motives and purposes for model construction

The motives and purposes to construct models in each of the three authentic practices were identified by document analysis and by expert interview. Afterwards the results of both methods were combined, checked and approved by the expert.

\section{$\underline{\text { Microbiological Risk Assessment }}$}

Food has to meet high standards regarding food safety and food quality to prevent food borne illnesses. Obviously, food manufacturers and the government are concerned because of public health reasons. Food manufacturers also have an economic interest besides public health. There is a growing tendency that consumers prefer ready-to-eat meals and more fresh and tasteful food. As a consequence more attention has to be paid to the microbiological safety of food. To control the safety of food, manufacturers are obliged by law to apply a proper hazard procedure. During manufacturing of food, several control systems are applied to control the microbiological quality of food. However, even with the best control measures in place, a food product may still pose a risk to the consumer. In order to quantify this risk, scientists and food manufacturers did join forces to work on a proper quantitative Microbiological Risk Assessment (MRA) to minimize the risk of food borne illnesses. The aim of this practice was to quantify the recontamination risk of food after inactivation steps in the production environment. 
Modelling drinking water treatment

The quality of drinking water is an important area within public health care. Different kinds of organic compounds, heavy metals and micro-organisms need to be removed to produce safe drinking water. Therefore several treatments methods are available, such as sand filtration and activated carbon filtration. In the Netherlands, the government and the drinking water production companies expect a growing drinking water demand due to an increase of the population and the level of prosperity. To supply for this extra demand, new sources for production of drinking water have to be found, or the use of existing sources need to be intensified. Since decisions on these matters have effects for a long period of time, it is necessary to have detailed information about future consequences. One would like to have data about the quality of the produced drinking water depending on the quality of the source, e.g. the un-treated water, and type, number and sequence of treatments steps. Such data can be provided with the use of a model predicting the quality of drinking water after treatment. The aim of this practice was to develop such a model consisting of modules representing separate steps in a drinking water treatment process.

\section{$\underline{\text { Human exposure assessment }}$}

Consumer products comprise a large diversity, ranging from shoe polish, to detergents and pesticides. All these products may contain hazardous chemicals. Consumers use all kinds of products for their personal convenience on a daily basis. In the Netherlands, the manufacturers themselves are responsible for the safety of their products for which they use different systems. A commonly used method is expert judgment. However, when a product is encountered with questionable health risks, also a quantitative judgment is needed about the actual human health risks. Many questions are encountered during human risk assessment. How to estimate exposure? Which exposure data are available? Are they representative for the situation in which the product is used? Which factors that control exposure are important? How to characterise risk? Which effects cause the main risks? On which time scale are effects 
relevant? The aim of this practice was to develop mathematical models, describing exposure and uptake of chemicals from consumer products, to assist in conducting a quantitative human risk assessment.

Characteristic modelling procedures

The characteristic modelling procedure in each of the three authentic practices was primarily distilled from document analysis. During the interview the expert reflected on the proposed procedure, resulting in several modifications and changes. The refined procedures were again submitted to the expert for a final check. Below the approved procedures are presented.

In Figure 2, the characteristic modelling procedures followed by employee(s) in the practices microbiological risk assessment, modelling drinking water treatment and human exposure assessment are presented. The actual modelling procedures all start with the authentic questions or problems, as described in the previous part on motives and purposes, and end with an evaluation with a sequence of activities in between. The flow of activities is compared with the stages in the general modelling procedure for students' (Webb, 1994), as depicted in Figure 2. The comparison reveals that the basic structure of the characteristic modelling procedures resemblances the stages in the general modelling procedure. Therefore, we expect that the characteristic modelling procedures are consistent with and linked with students' preexisting procedural modelling knowledge. That is, when students are confronted in a proper way with the starting authentic questions or problems, we expect that students do have a basic approach in mind resembling the authentic modelling procedures. It seems appropriate to use the characteristic modelling procedure as a guideline for designing a meaningful sequence of modelling activities from students' perspective.

\section{[Insert Figure 2 about here]}

Issue knowledge 
The issue knowledge involved in constructing models in each of the three authentic practices was firstly identified from document analysis. During the expert interview the respondent was asked to point out the main issue knowledge needed to act competently. The combined results regarding issue knowledge, as depicted below, were checked and approved by the expert.

\section{[Insert Table 4 about here]}

In Table 4 an overview of the involved issue knowledge in the practices microbiological risk assessment, modelling drinking water treatment and human exposure assessment is presented. All elements present Dutch science curricula at grade 11 are depicted in bold. These findings illustrate once again, but in much more detail, the multidisciplinary character of all three authentic practices. Furthermore, this overview of issue knowledge involved in each of the three practices gives some insight into the expected learning output when used as contexts. It can be concluded that the issue knowledge involved in modelling drinking water treatment and human exposure assessment correlates well with the actual content in chemistry (science) curricula. Many chemical (science) concepts are expected to be familiar to students in upper secondary chemistry education (age 16/17). In addition, both modelling drinking water treatment and human exposure assessment do offer some degree of flexibility with respect to specific issue knowledge needed, since in both cases different treatment steps and contaminants or consumer products, chemical substances and emission routes, can be selected or omitted to focus upon in classroom.

In case of microbiological risk assessment however, a relatively large number of elements that are not present in the Dutch science curricula can be distinguished, thus resulting in a negative judgement on criterion familiarity with the issue (C2). Moreover, microbiological risk assessment, unlike the other two models, puts a rather high demand on mathematical and technological background knowledge.

Research question 4: To what extent do these authentic chemical practices meet all criteria for selection as contexts for chemistry units? 
Based on the information gathered in the step 3 the three authentic chemical modelling practices were again reviewed to criteria students' interest (A1) and ownership (A2), the characteristic modelling procedure (B), complexity of the issue (C1), familiarity with the issue (C2) and practical feasibility of the laboratory work in classroom (D). The outcome is summarised in Table 5 .

\section{[Insert Table 5 about here]}

Two authentic practices are considered to be adequate to serve as contexts for designing curriculum units: modelling drinking water treatment and human exposure assessment. In this second evaluation step the practice microbiological risk assessment was judged low on criteria students' ownership (A2), familiarity with the issue (C2) and feasibility of laboratory work in classroom (D). It appeared that the motive to develop models is drawn from a long term need to control food safety. Apparently, one needs to be well informed in the field of food safety to gain some sense of importance of this long-term need. Such a long term motive seems less suitable to foster students' ownership with the problem at hand. Furthermore, in case of microbiological risk assessment, advanced background knowledge in biology, mathematics and technology is needed in order to act competently. Hence, the expected familiarity of students with the issue is judged low. With respect to issue knowledge, difficulties might be expected in managing the total cognitive load of students. Finally, this second evaluation revealed that implementing laboratory work for model calibration and validation in classroom will be difficult. In the first analysis, the familiarity of students with the issue was considered sufficiently and opportunities were seen to implement laboratory work in classroom. However, the literature study and consultation of the expert have lead to other judgements on these criteria.

In case of modelling drinking water treatment and human exposure assessment it is expected that students do experience ownership for the topic at hand due to clear motives and purposes for model construction from student's perspective. The characteristic modelling procedures in 
both practices are expected to be in line with students' common sense notions and preexisting procedural modelling knowledge. The depicted modelling procedures are applicable to a choice of treatment steps and contaminants, or consumer products, chemical substances and emission routes, thus facilitating implementation in classroom. Both practices do offer opportunities to implement real experiments for model calibration and validation in the classroom. Results on the issue knowledge involved indicated that it seems possible to build upon the existing knowledge base of students.

In conclusion to this step-wise selection procedure to search, select, analyse and evaluate authentic practices to be used for modelling education, we formulate the answer on research question 4 as follows. Both modelling drinking water treatment and human exposure assessment meet the criteria to a large extent. The results show that both practices are within the students' zone of proximal development and thus are potentially usable as contexts for the design of meaningful units for the learning of models and modelling.

\section{Conclusions and discussion}

In the final section of this paper, the results described above are discussed in relation to the purpose of this study. The present study has sought to select authentic chemical modelling practices as contexts for meaningful learning of models and modelling, based on activity theory rooted in sociocultural theories on learning. Authentic practices provide guidelines for designing context-based units. These guidelines are the motives and purposes for model construction, the characteristic modelling procedure employed, and the involved issue knowledge. Not all authentic practices are suitable for use in upper secondary chemistry education. Therefore we formulated a set of criteria for selecting and evaluating authentic practices. This study revealed two authentic chemical modelling practices which can serve as a context for unit design. Both practices meet all formulated criteria to a large extent. The motives for model development appeared to emerge from clear problems or questions, which seem recognisable from the students' perspective. The characteristic modelling procedure 
corresponds to a large degree with students' expected common sense procedural knowledge,

and thus can be used to design a coherent sequence of modelling activities in classroom. One of the challenges in adapting an authentic practice into an instructional version is to account for the differences in issue knowledge between experts and students. Both practices can be elaborated flexibly, for instance by focusing on well chosen treatment steps or chemical substances within consumer products, thus establishing a solid connection with students' preexisting knowledge base.

However, one should consider that these conclusions are situated within the Dutch perspective. Therefore only Dutch websites were reviewed reporting about essentially Dutch authentic issues. As a consequence, Dutch experts were interviewed. Finally, the involved issue knowledge in the authentic practices was compared to the actual Dutch chemistry (science) curriculum.

By describing this starting point of selecting authentic practices for the design of units in which students should experience the meaningfulness of learning models and modelling, we also contribute to the development of contexts-based units in science education. This method to select and evaluate practices for use as contexts might be of use in other science domains. Furthermore, we have indicated in what way the essential features of those practices will be of use during the design of such context-based curriculum units.

Over the past years, models and modelling has been studied from several perspectives, like students' understanding of specific models in physics and chemistry, the process of modelling, teachers' knowledge and use of models in science education and how modelling can be approached gradually in the classroom (Gilbert \& Boulter, 2000; Harrison \& Treagust, 1996; Justi \& Gilbert, 2002; Treagust, Chittleborough, \& Mamiala, 2002; Van Driel \& Verloop, 2002). Most of these studies focus primarily on models that already, for historical reasons, have been incorporated in science curricula describing or explaining phenomena regarded as representative for that domain. However, major learning problems related to models and modelling are still apparent. The strategy described in this paper builds on recommendations in literature to focus on the process of modelling and the use of models 
(Penner, Lehrer, \& Schauble, 1998; Roth, 1998). Our approach implies that the modelling procedure in an authentic practice determines, to a large extent, the design of a curriculum unit. The selected authentic practices are considered within the students' zone of proximal development, in contrast to many 'typical' traditional research practices from which the issue knowledge can be found in traditional science curricula. The use of a relatively open internet search method as described proved to be successful in finding practices in which students can recognize real-life problems and societal issues (Bennett \& Holman, 2002; Edelson, 1998). Furthermore, in a curriculum unit based on the selected practices students are engaged in authentic modelling approach with an explicit attention for motives and purposes to construct models. In our opinion, such an unit significantly promotes students' understanding of the role and functioning of models in society (Gobert \& Pallant, 2004). In addition, students are expected to recognise that models and modelling in chemistry matters for society and thus can be relevant for themselves. We consider this as an important goal for chemistry education and science education in general.

Although this study has revealed two promising authentic practices, further research is needed to evaluate the potential benefits of this strategy. This includes an analysis of the adaptation of the selected authentic chemical modelling practices into instructional versions, teacher preparation, classroom practice and outcomes in terms of students' insight in the functioning and meaning of models in science. Preceding the full design of an authentic practice based unit, we consider it appropriate to gain more certainty in the potential success of our efforts. In our view meaningful learning of models and modelling by students can only be achieved if students indeed feel a need for modelling and have some sense of direction in terms of a sequence of modelling activities. Since these values should emerge in the beginning of an unit, we plan to study empirically the start of both selected authentic practice based units in a forum group of students using the method of developmental research (Bulte, Westbroek, De Jong, \& Pilot, 2006; Lijnse, 1995). The next step will be designing a complete unit to be tested in real classroom situations. This research phase needs to be accompanied with well planned teacher preparation, since both model use and outlining of the unit will be very 
different compared to normal chemistry classes. However, given the fact that model-based teaching and learning is regarded as central in science education, it is worth while to explore this strategy, and to evaluate the potential benefits in classroom and the possible contribution to the design of context-based units in science education.

\section{$\underline{\text { Acknowledgements }}$}

The authors wish to thank Remko Boom, Professor of Food and Bioprocess Engineering at Wageningen University, The Netherlands, Ans Versteegh, Head Policy Advice and Research Drinking Water and Mark van Veen, researcher at Netherlands Environmental Assessment Agency, both employed at the National Institute of Public Health and the Environment, for their contribution to this research study.

\section{References}

Bennett, J., \& Holman, J. (2002). Context-based approaches to the teaching of chemistry: what are they and what are their effects? In J. K. Gilbert, O. De Jong, R. Justi, D. F. Treagust \& J. H. Van Driel (Eds.), Chemical Education: Towards Research-based practice (pp. 165-184). Dordrecht, The Netherlands: Kluwer Academic Press.

Bulte, A. M. W., Klaassen, K., Westbroek, H. B., Stolk , M. J., Prins, G. T., Genseberger, R., De Jong, O., \& Pilot, A. (2005). Modules for a new chemistry curriculum, research on a meaningful relation between contexts and concepts. In P. Nentwig \& D. Waddington (Eds.), Context based learning of science (pp. 273-299). Münster, Germany: Waxmann.

Bulte, A. M. W., Westbroek, H. B., De Jong, O., \& Pilot, A. (2006). A research approach to designing chemistry education using authentic practices as contexts. International Journal of Science Education, 28(9), 1063-1086.

Carey, S. (1985). Are Childeren fundamentally different kinds of thinkers than adults? In Thinking and Learning Skills (Vol. 2, pp. 485-517). Hillsdale Lawrence Erlbaum. 
Confrey, J. (1995). How compatible are radical constructivism, sociocultural approaches and social constructivism? In L. P. Steffe \& J. Gale (Eds.), Constructivism in education (pp. 185-226). Hillsdale, New Jersey: Lawrence Erlbaum.

Den Aantrekker, D. E. (2002). Recontamination in food processing-quantitative modelling for risk assessment. Wageningen University, Wageningen.

Donnelly, J. (2001). Contested terrain or unified project? 'The nature of science' in the National Curriculum for England and Wales. International Journal of Science Education, 23(2), 181-195.

Duschl, R. A., \& Gitomer, D. (1997). Strategies and challenges to changing the focus of assesment and instruction in science classrooms. Educational Assessment, 4(1), 37-73.

Edelson, D. C. (1998). Realising Authentic Science Learning through the Adaptation of Scientific Practice. In B. J. Fraser \& K. G. Tobin (Eds.), International Handbook of Science Education (Vol. 1). Dordrecht: Kluwer.

Engestroem, Y. (1987). Learning by expanding: An activity-theoretical approach to developmental research. Helsinki: Orienta-Konsultit.

Erduran, S. (2001). Philosophy of chemistry: an emerging field with implications for chemistry education. Science \& Education, 10(6), 581-593.

Erduran, S., \& Duschl, R. A. (2004). Interdisciplinary Characterizations of models and the Nature of Chemical Knowledge in the Classroom. Studies in Science Education, 40, $105-138$.

Giere, R. (1988). Explaining Science. Chicago: The University of Chicago Press.

Gilbert, J. K. (2006). On the Nature of "Context" in Chemistry Education. International Journal of Science Education, 28(9), 957-976.

Gilbert, J. K., \& Boulter, C. J. (1998). Learning science though models and modelling. In B. J. Fraser \& K. G. Tobin (Eds.), International Handbook of Science Education (Vol. I, pp. 53-66). Dordrecht: Kluwer Academic Publishers.

Gilbert, J. K., \& Boulter, C. J. (2000). Developing Models in Science Education. Dordrecht: Kluwer Academic Publishers. 
Gobert, J. D., \& Buckley, B. (2000). Special issue editorial: Introduction to model-based teaching and learning. International Journal of Science Education, 22(9), 891-894.

Gobert, J. D., \& Pallant, A. (2004). Fostering Students' Epistemologies of Models via Authentic Model-Based Tasks. Journal of Science Education and Technology, 13(1), 721.

Grosslight, L., Unger, C., Jay, E., \& Smith, C. (1991). Understanding models and their use in science: conceptions of middle and high school students and experts. Journal of Research in Science Teaching, 28(9), 799-822.

Harrison, A. G., \& Treagust, D. F. (1996). Secondary students' mental models of atoms and molecules: implications for teaching science. Science Education, 80(5), 509-534.

Harrison, A. G., \& Treagust, D. F. (2000). A typology of school science models. International Journal of Science Education, 22(9), 1011-1026.

Hmelo-Silver, C. E., Nagarajan, A., \& Day, R. S. (2002). "It's Harder than We Though It Would be": A Comparative Case Study of Expert-Novice Experimentation Strategies. Science \& Education, 86, 219-243.

Hodson, D. (1992). In search of a meaningful relationship: an exploration of some issues relating to integration in science and science education. International Journal of Science Education, 14, 541-562.

Ingham, A. M., \& Gilbert, J. K. (1991). The use of analogue models by students of chemistry at higher education level. International Journal of Science Education, 13, 193-202.

Jacobsen, E. K. (2004). Water Filtration. Journal of Chemical Education, 81(2), 224.

Justi, R. S., \& Gilbert, J. K. (2002). Modelling, teachers' views on the nature of modelling, and implications for the education of modellers. International Journal of Science Education, 24(4), 369-387.

Kuhn, D. (1989). Children and Adults as Intuitive Scientists. Psychological Review, 96(4), 674-689.

Leont'ev, A. N. (1978). Activity, Consciousness and Personality. Englewood Cliffs, New Yersey: Prentice-Hall, Inc. 
Lijnse, P. L. (1995). 'Developmental Research' as a way to empirically based 'Didactical Structure of Science'. Science Education, 79(2), 189-199.

Osborne, J., \& Collins, J. (2001). Pupils' Views of the Role and Value of the Science Curriculum: a Focus-group Study. International Journal of Science Education, 23(5), 441-467.

Penner, D. E., Lehrer, R., \& Schauble, L. (1998). From physical models to biomechanics: A design-based modeling approach. . The Journal of the Learning Sciences 7(3-4), 429449.

Pilot, A., \& Bulte, A. M. W. (2006). The use of 'contexts' as a challenge for the chemistry curriculum: its successes \& the need for further development and understanding. International Journal of Science Education, 28(9), 1087-1112.

Psarros, N. (1998). What has philosophy to offer to chemistry? Foundations of Science, 1, $183-202$.

Roth, W.-M. (1996). Knowledge diffusion in a grade 4-5 classroom during a unit of civil engineering: An analysis of classroom community in terms of its changing resources and practices. . Cognition and Instruction, 14, 170-220.

Roth, W.-M. (1998). Designing communities. Dordrecht: Kluwer Academic Publishers.

Sabelli, N. (1994). On using technology for understandings science. Interactive Learning Environments, 4(3), 195-198.

Schauble, L., Klopfer, L. E., \& Raghavan, K. (1991). Students' transition from an engineering model to a science model of experimentation. Journal of Research in Science Teaching, $8,859-882$.

Schunn, C. D., \& Anderson, J. R. (1999). The Generality/Specificity of Expertise in Scientific Reasoning. Cognitive Science, 23(3), 337-370.

Smith, J. A. (1995). Semi-structured interviewing and qualitative analysis. In J. A. Smith, R. Harre \& L. Van Langenhove (Eds.), Rethinking Methods in Psychology. (pp. 9-26). Thousand Oaks: Sage. 
Taconis, R., Ferguson-Hessler, M. G. M., \& Broekkamp, H. (2001). Teaching Science

Problem Solving: An Overview of Experimental Work. Journal of Research in Science Teaching, 38(4), 442-468.

Treagust, D. F., Chittleborough, C., \& Mamiala, T. L. (2002). Students' understanding of the role of scientific models in learning science. International Journal of Science Education, 24(4), 357-368.

Van Aalsvoort, J. (2004). Activity theory as a tool to address the problem of chemisrty's lack of relevance in secondary school chemical education. International Journal of Science Education, 26(13), 1635-1651.

Van Driel, J. H., \& Verloop, N. (2002). Experienced teachers' knowledge of teaching and learning of models and modelling in science education. International Journal of Science Education, 24(12), 1255-1272.

Van Oers, B. (1998). From context to contextualizing. Learning and Instruction, 8, 473-488.

Van Veen, M. P. (2001). CONSEXPO 3.0: Consumer exposure and uptake models (No. 612810011). Bilthoven: National Institute of Public Health and the Environment.

Versteegh, J. F. M., Van Gaalen, F. W., Rietveld, E. G., Aldenberg, T. A., \& Cleij, P. (2001). TAPWAT: Definition, structure and applications for modelling drinking-water treatment (No. 734301019). Bilthoven: National Institute of Public Health and the Environment.

Vygotsky, L. S. (1978). Mind in Society. The development of higher psychological processes. Cambridge: Harvard University Press.

Webb, M. E. (1994). Beginning computer-based modelling in primary schools. Computers in Education, 22(1), 129-144.

Westbroek, H. B. (2005). Characteristics of Meaningful Chemistry Education. Utrecht: CD-ß Press. 


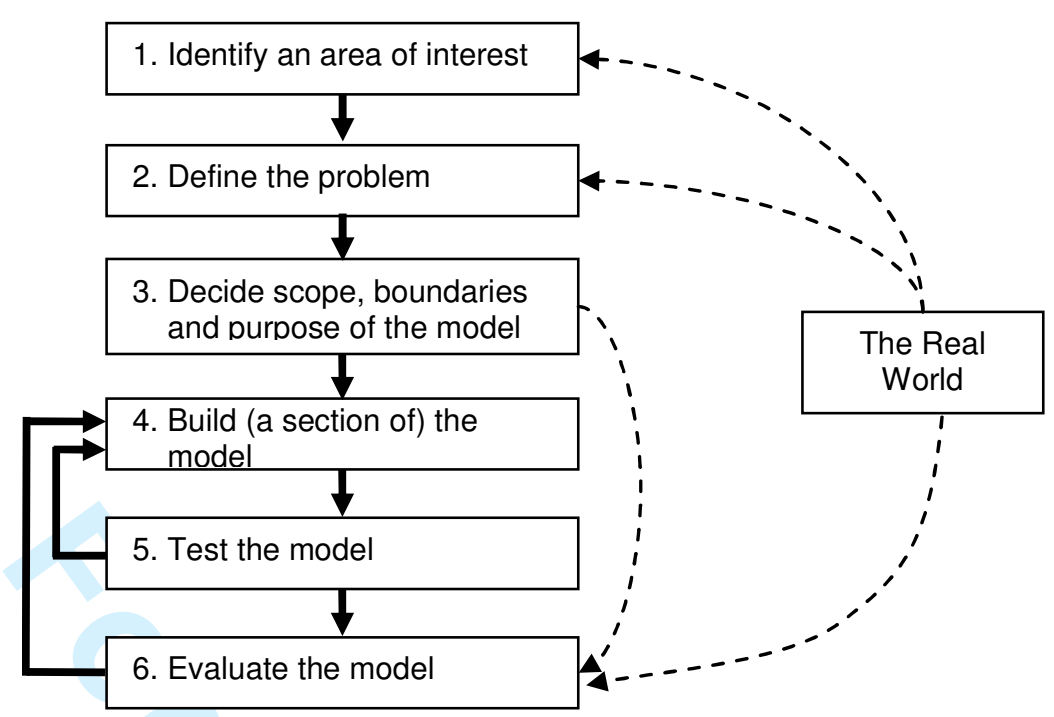

Figure 1: A six-stage modelling process for general application, originating from the Modus project. Bold lines indicate the direction of the process, the dotted lines represent the flow of information (Webb, 1994). 
1

Characteristic modelling procedures

2

${ }_{3}^{2}$ General $\quad$ Microbiological risk assessment

4

$5^{\text {Identify }}$

6 area of

$7^{\text {interes }}$

I

8 Define

9 problem

10

11

12

1 Becide on

1 stope,

15 oundaries

1 हnd

1 purpose

18

19

20

21

22

23

24

25

26

27

28

29

3Build

3(section) of 3model

33

34

35

36

37

38

39

40

41

$42^{\text {Tes }}$

43

44

45

46

47

48

49

50

51

52

53

54

55

56

57

\begin{tabular}{|l|l|}
\hline $\begin{array}{l}\text { Quantify recontamination } \\
\text { risk in food production }\end{array}$ & $\begin{array}{l}\text { Growing drink water } \\
\text { demand results in need }\end{array}$ \\
\hline
\end{tabular}

risk in food production

$\longrightarrow$ environment

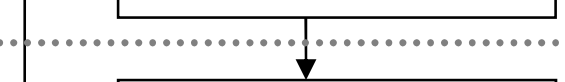

Describing new features to

be added to existing model MRA

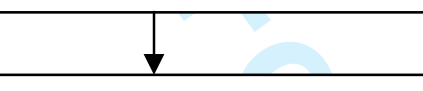

Identification, description and selection of the main sources of recontamination in food production environment

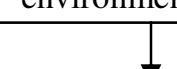

Describing the processes of recontamination

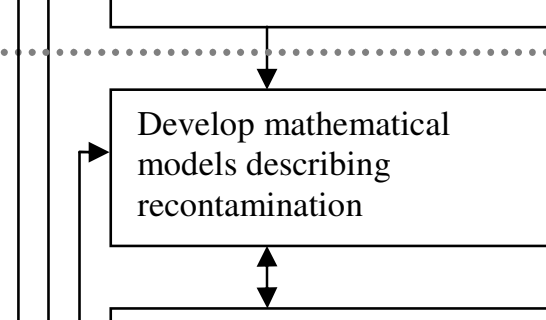

Collect experimental data to calibrate model

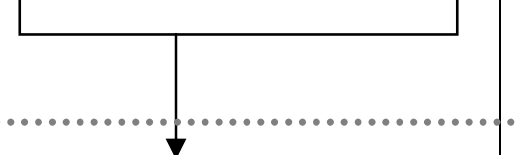

Validate model by calculating recontamination risk in real situations and compare with empirical data

demand results in need for

new tap sources or/and

intensified use of existing

sources: extra pressure on

treatment process

Predict the quality of drink

water of treatment

Human exposure assessment

$\longrightarrow$

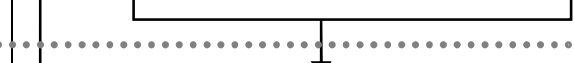

Quantify human exposure and uptake to chemicals out of consumer products. Develop additional method next to existing expert judgement

Describe exposure routes of chemicals from consumer products to humans. routes of chemical
compounds from product
Validate model by applying in real situations
Selection of chemical compounds and microorganisms to take into account

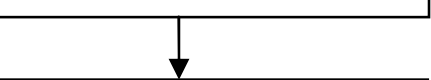

Selection of relevant treatment steps including process parameters

Collect empirical data for model development or use available company data

Develop mathematical models by statistical techniques

$$
\text { L }
$$

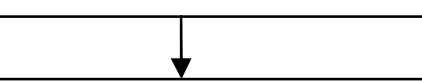

Identification of hazardous chemical compounds per product

\begin{tabular}{|l|}
\hline \multicolumn{1}{|c|}{ Identification of exposure } \\
routes of chemical \\
compounds from product
\end{tabular}

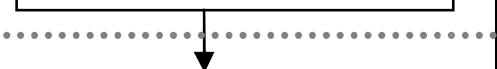

Develop mathematical models describing exposure

Quantification of relevant parameters by experiments
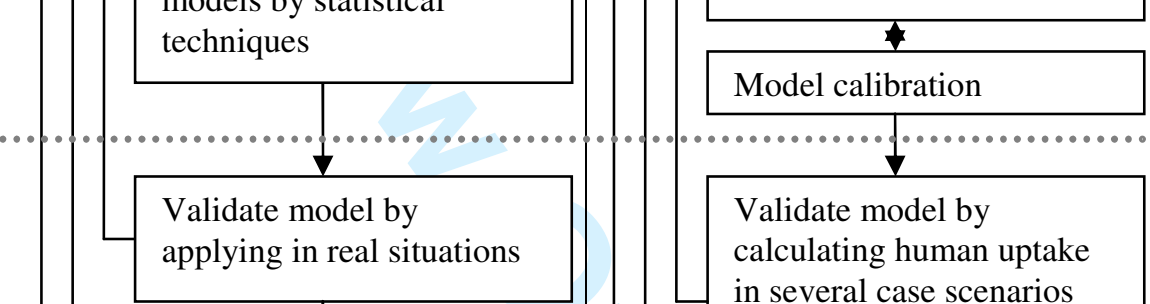
1

Validate model by calculating human uptake in several case scenarios and combine with expert judgement 
Table 1: Scheme for the semi-structured expert interview

Feature A: Motive to develop models

1. Which (type of) questions or problems led to the development of models?

2. Can you mention some concrete examples of those questions or problems?

3. Why did these questions or problems evoke the need for a model?

Feature B: Characteristic modelling procedure

4. Can you describe the development of the models in a sequence of activities?

a. What information was used in each stage?

b. What specific actions were taken in every stage?

Feature C: Issue knowledge

5. What issue knowledge and skills do you consider important for somebody working on these kinds of questions or problems? 
Table 2: Short description of the seven topics of the practices resulting from the internet search

\begin{tabular}{|c|c|c|}
\hline Topics of the practice & $\begin{array}{l}\text { Number of } \\
\text { references from } \\
\text { internet search }\end{array}$ & Short description \\
\hline Climate modelling & 7 & $\begin{array}{l}\text { Modelling circulation of chemical substances in the troposphere } \\
\text { to predict climate changes. }\end{array}$ \\
\hline Microbiological risk assessment & 2 & $\begin{array}{l}\text { Modelling microbiological (re)contamination in food chains to } \\
\text { predict food safety. }\end{array}$ \\
\hline $\begin{array}{l}\text { Modelling emissions of volatile } \\
\text { organic substances }\end{array}$ & 3 & $\begin{array}{l}\text { Modelling emission of volatile organic substances to predict } \\
\text { safety of factory environments. }\end{array}$ \\
\hline $\begin{array}{l}\text { Modelling drinking water } \\
\text { treatment }\end{array}$ & 4 & $\begin{array}{l}\text { Modelling the water treatment process to predict the quality of } \\
\text { drinking water out of surface water. }\end{array}$ \\
\hline $\begin{array}{l}\text { Model-based predictive control } \\
\text { of food production }\end{array}$ & 5 & $\begin{array}{l}\text { Modelling treatments steps in food production to predict the } \\
\text { food quality, - variation and process efficiency. }\end{array}$ \\
\hline Human exposure assessment & 4 & $\begin{array}{l}\text { Modelling human exposure and uptake to chemicals emitted by } \\
\text { consumer products to predict safety of consumer products. }\end{array}$ \\
\hline Modelling a biogas installation & 4 & Modelling a biogas installation to predict energy supply. \\
\hline
\end{tabular}


1

2

3

4

5

6

7

8

9

10

11

12

13

14

Table 3: Combined results of independent judgement by two researchers of the seven practices with respect to criteria: students' interest (A1), complexity of the issue (C1), familiarity with the issue (C2) and feasibility of the laboratory work in classroom (D).

\begin{tabular}{|c|c|c|c|c|}
\hline & $\begin{array}{l}\text { Students' } \\
\text { interest }(A 1)\end{array}$ & $\begin{array}{l}\text { Complexity } \\
(C 1)\end{array}$ & $\begin{array}{l}\text { Familiarity } \\
\qquad(C 2)\end{array}$ & $\begin{array}{l}\text { Laboratory } \\
\text { work }(D)\end{array}$ \\
\hline Climate modelling & + & - & - & - \\
\hline Microbiological risk assessment & + & + & + & + \\
\hline $\begin{array}{l}\text { Modelling emissions of volatile } \\
\text { organic substances }\end{array}$ & - & $\begin{array}{c}+ \\
-------\end{array}$ & + & $\begin{array}{c}- \\
--------\end{array}$ \\
\hline Modelling drinking water treatment & + & + & + & + \\
\hline $\begin{array}{l}\text { Model-based predictive control of food } \\
\text { production }\end{array}$ & + & - & - & - \\
\hline Human exposure assessment & + & + & + & + \\
\hline Modelling a biogas installation & + & + & + & - \\
\hline
\end{tabular}

+ Positive judgement with respect to use in chemistry education at upper secondary level

- Negative judgement with respect to use in chemistry education at upper secondary level 


\begin{tabular}{|c|c|c|c|}
\hline $\begin{array}{l}\text { Domain of } \\
\text { issue } \\
\text { knowledge }\end{array}$ & $\begin{array}{c}\text { Microbiological risk } \\
\text { assessment }\end{array}$ & Modelling drinking water treatment & Human exposure assessment \\
\hline $\begin{array}{l}\text { Chemistry / } \\
\text { technology }\end{array}$ & $\begin{array}{l}\text { Mass- and heat transfer } \\
\text { Flow characteristics of complex, } \\
\text { heterogeneous media at different size } \\
\text { and timescales }\end{array}$ & $\begin{array}{l}\text { Water contaminants: } \\
\text { Inorganic / organic contaminants } \\
\text { Disinfection products } \\
\text { Pesticides } \\
\text { Chemical treatment processes: } \\
\text { Precipitation / coagulation / flocculation } \\
\text { Activated carbon filtration } \\
\text { Aeration / ozonation } \\
\text { Drinking water supply: } \\
\text { Drinking water quality parameters } \\
\text { Infrastructure of drinking water supply } \\
\text { Environmental Outlook }\end{array}$ & $\begin{array}{l}\text { Mixtures / pure substances / solvents } \\
\text { Concentration (weight fraction) } \\
\text { Evaporation characteristics } \\
\text { Mass balances for evaporation } \\
\text { Diffusion } \\
\text { Chemical identification of substances } \\
\text { Molecular structure of substances }\end{array}$ \\
\hline Biology & $\begin{array}{l}\text { Physiology and taxonomy of micro- } \\
\text { organisms (bacteria, fungi, viruses, } \\
\text { etc.) } \\
\text { Metabolic flux analysis to describe } \\
\text { behaviour of micro-organisms during } \\
\text { stress periods } \\
\text { 'Predictive' microbiology (develop } \\
\text { quantitative models to describe } \\
\text { behaviour of micro-organisms) }\end{array}$ & $\begin{array}{l}\text { Biological treatment processes: } \\
-\quad \text { Flocculation / settling } \\
-\quad \text { Slow (rapid) sand filtration } \\
\text { Health risks and dangers of bacteria: } \\
-\quad \text { Enterovirusses } \\
-\quad \text { Giarda } \\
-\quad \text { Cryptosporidia }\end{array}$ & $\begin{array}{ll}\text { Dose-effect relations: } \\
- & \text { Long term average vs. acute } \\
- & \text { Worst case dose } \\
- & \text { Standard dose } \\
\text { Contact: } & \\
- & \text { Exposure (chemical) } \\
- & \text { Uptake (breath in, skin, month) } \\
- & \text { Scenario's (duration, frequency) }\end{array}$ \\
\hline Mathematics & $\begin{array}{l}\text { Statistical analysis of large data sets } \\
\text { Differential equations } \\
-\quad \text { partial } \\
-\quad \text { numeric } \\
\text { analytical } \\
\text { Develop and analyse complex models } \\
\text { for metabolic flux analysis } \\
\text { Symbolic and numerical solutions } \\
\text { Experimental/statistical experiments }\end{array}$ & $\begin{array}{ll}\text { Statistics: } \\
- & \text { Averages } \\
- & \text { Standard deviation } \\
- & \text { Regression analysis }\end{array}$ & $\begin{array}{ll}\text { Statistics: } \\
- & \text { Averages } \\
- & \text { Standard deviation } \\
- & \text { Distributions: } \\
\text { - mean } \\
\text { - uniform } \\
\text { - empirical } \\
\text { Differential equations }\end{array}$ \\
\hline Modelling & $\begin{array}{l}\text { The skills to select from experimental } \\
\text { observations the essential factors or } \\
\text { conditions needed to describe or explain } \\
\text { a phenomena and to use them develop a } \\
\text { simple model capable to describe the } \\
\text { dependence of the factors in the } \\
\text { phenomena. } \\
\text { Draw up and analyze physical } \\
\text { mechanisms aimed to develop simple } \\
\text { models } \\
\text { 'Data driven modelling' }\end{array}$ & $\begin{array}{l}\text { Empirical / systematic modelling approach } \\
\text { Predictive value of models: } \\
-\quad \text { uncertainties } \\
-\quad \text { reliability } \\
\text { Risk balancing }\end{array}$ & $\begin{array}{l}\text { Systematic modelling approach } \\
\text { Categorisation of consumer products } \\
\text { Dealing with uncertainties } \\
\text { Risk assessment }\end{array}$ \\
\hline
\end{tabular}

Table 4: An overview of involved issue knowledge in microbiological risk assessment, modelling drinking water treatment and human exposure assessment, approved and checked by the experts. In bold are depicted elements present in Dutch science curricula at grade 11 
Table 5: Combined results of independent judgement by two researchers of microbiological risk assessment, modelling drinking water treatment and human exposure assessment with respect to criteria: students' interest (A1), students' ownership (A2), modelling procedure (B) complexity of the issue $(\mathrm{C} 1)$, familiarity with the issue $(\mathrm{C} 2)$ and feasibility of the laboratory work in classroom (D).

\begin{tabular}{|l|c|c|c|c|c|c|}
\hline & $\begin{array}{c}\text { Students } \\
\text { interest } \\
(A 1)\end{array}$ & $\begin{array}{c}\text { Students } \\
\text { ownership } \\
(A 2)\end{array}$ & $\begin{array}{c}\text { Modelling } \\
\text { procedure } \\
(B)\end{array}$ & $\begin{array}{c}\text { Complexity } \\
(C 1)\end{array}$ & $\begin{array}{c}\text { Familiarity } \\
(C 2)\end{array}$ & $\begin{array}{c}\text { Laboratory } \\
\text { work } \\
(D)\end{array}$ \\
\hline $\begin{array}{l}\text { Microbiological risk } \\
\text { assessment }\end{array}$ & + & - & + & + & - & - \\
\hline $\begin{array}{l}\text { Modelling drinking } \\
\text { water treatment }\end{array}$ & + & + & + & + & + & + \\
\hline $\begin{array}{l}\text { Human exposure } \\
\text { assessment }\end{array}$ & + & + & + & + & + & + \\
\hline
\end{tabular}

+ Positive judgement with respect to use in chemistry education at upper secondary level

- Negative judgement with respect to use in chemistry education at upper secondary level 